\title{
GANGGUAN POLA NAPAS TIDAK EFEKTIF PADA PASIEN ACUTE MYOCARD INFARK (AMI)
}

\author{
Vera Budi Nurani ${ }^{1}$, Yuyun Setyorini ${ }^{2}$, Akhmad Rifai $^{3}$ \\ ${ }^{1,2,3,}$ Poltekkes Kemenkes Surakarta, Jurusan Keperawatan \\ Diterima : 2 Oktober 2018 , Disetujui : 10 Oktober 2018 \\ e-mail: vbn_ska@yahoo.com
}

\begin{abstract}
Background: Acute Myocard Infarction (AMI) is the death of cardiac muscle cells due to long-lasting ischemia due to grafting in the coronary arteries. One of the nursing interventions is giving proper oxygen because it affects the condition of the patient who is short of breath. The aim of this study was to describe nursing care in patients with Acute Myocard Infarction (AMI) with impaired breathing disorder. Methods: This research uses data analysis method that is comparing the result criteria achieved from two patients of Acute Myocard Infarction (AMI) who experienced ineffective breathing disorder and then compared with case study journal or other sources. Result: Based on interview and observation it is concluded that with the same nursing diagnoses and implementation there are differences in outcomes and responses between the intervention group and the control group. Suggestion: Suggestions put forward in this study is the need to pay attention to accuracy in conducting assessment to maximize data to determine the priority problems that occur in patients and interventions based ONEC (Observation, Nursing Treatment, Education, Collaboration).
\end{abstract}

\section{Keywords : Acute Myocard Infarction, Breath Pattern Not effective}

\section{PENDAHULUAN}

Acute Myocard Infark (AMI) didefinisikan sebagai nekrosis miokardium yang disebabkan oleh tidak adekuatnya pasokan darah akibat sumbatan akut arteri koroner. Sumbatan ini sebagian besar disebabkan oleh ruptur plak ateroma pada arteri koroner yang kemudian diikuti trombosis, vasokonstriksi, reaksi inflamasi, dan mikroembolisasi distal (Muttaqin, 2009).

Berdasarkan laporan World Health Statistic 2010, penyakit tidak menular merupakan penyebab utama 58 juta kematian di dunia. Meliputi penyakit jantung dan pembuluh darah (30\%), penyakit pernafasan kronik dan penyakit kronik lainnya (16\%), kanker (13\%), cedera $(9 \%)$ dan diabetes melitus $(2 \%)$. Tercatat 17,1 juta orang meninggal dunia akibat penyakit jantung dan diperkirakan angka ini akan meningkat terus hingga 2030 menjadi 23,4 juta kematian di dunia (Depkes, 2011).

Berdasarkan data Departemen Kesehatan RI, menunjukkan bahwa kematian karena penyakit kardiovaskuler termasuk penyakit jantung koroner adalah sebesar 26,4\%. Dan sampai dengan saat ini penyakit jantung koroner juga merupakan penyebab utama kematian dini pada sekitar $40 \%$ dari sebab kematian laki-laki usia menengah. Direktorat Jendral Yanmedik Indonesia meneliti pada tahun 2009, jumlah pasien penyakit jantung yang menjalani rawat inap dan 
rawat jalan di RS di Indonesia adalah 239.548 jiwa. Kasus terbanyak adalah penyakit iskemik yaitu 110.183 kasus. Care Fatality Rate (CFR) tertinggi terjadi pada Acute Myocard Infark (AMI) $(13,37 \%)$ dan kemudian diikuti gagal jantung $(13,42 \%)$ dan penyakit jantung lainnya (13,37\%) (Depkes, 2011).

Prevalensi jantung koroner berdasarkan wawancara terdiagnosis dokter di Indonesia sebesar 0,5 persen, dan berdasarkan terdiagnosis dokter atau gejala sebesar 1,5 persen. Prevalensi jantung koroner berdasarkan terdiagnosis dokter tertinggi Sulawesi Tengah $(0,8 \%)$ diikuti Sulawesi Utara, DKI Jakarta, Aceh masing-masing 0,7 persen. Sementara prevalensi jantung koroner menurut diagnosis atau gejala tertinggi di Nusa Tenggara Timur $(4,4 \%)$, diikuti Sulawesi Tengah (3,8\%), Sulawesi Selatan (2,9\%), dan Sulawesi Barat $(2,6 \%)$. Sedangkan di Jawa Tengah $(0,5 \%)$ (Riskesdas, 2013).

Berdasarkan data yang diperoleh dari rekam medik RSUD dr. Moewardi tahun 2015 diperoleh data prevalensi penderita Acute Myocard Infark (AMI) di ruang ICVCU pada tahun 2013 sebanyak 183 pasien, sedangkan pada tahun 2014 meningkat menjadi 292 pasien, dan tahun 2015 meningkat menjadi 325 pasien (Yudha, 2016).

Acute Myocard Infark (AMI) merupakan kematian sel-sel otot jantung karena iskemia yang berlangsung lama akibat adanya okulasi di arteri koroner. Penyumbatan ini dapat meluas dan mengganggu suplai oksigen ke seluruh tubuh. Gangguan suplai oksigen pada pasien Acute Myocard Infark (AMI) tidak terelakkan karena suplai oksigen menurun akibat dari pemompaan yang tidak efektif, sedangkan semakin banyak sel yang harus disuplai oksigen. Berkurangnya suplai oksigen pada jantung dapat mengakibatkan nekrosis miokardium. Maka jantung akan dengan melakukan metabolisme anaerob agar jantung tetap memberikan suplai oksigen keseluruh tubuh (Thygesen, Alpert, Jaffe, Simoons, Chaitman \& White, 2012).

Menurut Kastron (2012), hasil dari metabolisme anaerob berupa asam laktat, inilah yang menyebabkan nyeri dada seperti diremas-remas, ditekan, ditusuk, panas, atau ditindih barang berat pada dada depan (bawah sternum) serta menjalar ke dagu, leher kiri, punggung, dan epigastrium. Nyeri dada disertai sesak nafas. Akan tetapi sesak nafas (dyspnea cardiac) juga dapat ditemukan pada awal serangan. Sesak nafas terjadi karena pengerahan tenaga dan kenaikan tekanan akhir diastolic ventrikel kiri yang meningkatkan tekanan vena pulmonalis. Aktivitas pasien seringkali juga mengalami perubahan. Pasien sering merasa kelemahan, kelelahan, tidak dapat tidur, dan pola hidup menetap (bedrest). Karena aktivitas dapat memicu peningkatan kerja jantung, sehingga sesak nafas dan nyeri dada dapat timbul kembali. Akibat pengalaman ketidaknyamanan tersebut serta kekhawatiran terhadap proses keperawatan dan ancaman kematian, seringkali menimbulkan berbagai permasalahan psikologis bagi pasien, diantaranya kecemasan, cenderung diam, dan menarik diri.

Berdasarkan pengalaman di rumah sakit, pemberian oksigen pada pasien Acute Myocard Infark (AMI) sangat diperhatikan karena mempengaruhi kondisi pasien yang sesak napas dan perubahan saturasi oksigen. Selain itu pemberian oksigen yang tepat akan 
mencegah perluasan infark dan menurunkan kerja miokard akibat kekurangan suplai oksigen.

\section{METODE PENELITIAN}

Dalam penyusunan Karya Tulis Ilmiah ini penulis menggunakan jenis rancangan deskriptif. Menurut Nursalam (2016) desain studi kasus deskriptif bertujuan untuk memaparkan peristiwaperistiwa penting yang terjadi pada masa kini. Deskripsi peristiwa dilakukan secara sistematis dan lebih menekankan pada data faktual daripada penyimpulan. Fenomena disajikan secara apa adanya tanpa manipulasi dan tidak dianalisis bagaimana dan mengapa fenomena tersebut bisa terjadi, oleh karena itu rancangan deskriptif ini tidak memerlukan adanya suatu hipotesis.

Jenis rancangan deskriptif yang digunakan dalam Karya Tulis Ilmiah ini adalah rancangan penelitian studi kasus. Studi kasus merupakan rancangan penelitian yang mencakup pengkajian satu unit penelitian secara intensif misalnya klien, keluarga, kelompok, komunitas atau institusi. Rancangan dari suatu studi kasus bergantung pada keadaan kasus namun tetap mempertimbangkan faktor penelitian waktu. Keuntungan yang paling besar dari rancangan ini adalah pengkajian secara terperinci meskipun jumlah responden sedikit, sehingga akan didapatkan gambaran unit subjek secara jelas (Nursalam, 2016).

Studi kasus ini bertujuan untuk memberikan gambaran tentang Asuhan Keperawatan pada pasien Acute Myocard Infark (AMI) dengan gangguan pola napas tidak efektif yang meliputi pengkajian, diagnosa, intervensi, implementasi sampai dengan evaluasi keperawatan melalui wawancara dan observasi sehingga desain studi kasus ini menggunakan jenis dan rancangan deskriptif dengan pendekatan studi kasus.

\section{HASIL PENELITIAN}

Dalam sub bab ini akan membahas mengenai asuhan keperawatan pada Ny. A dan Ny. S dengan Non ST - Elevasi Miokardium (NSTEMI) dengan gangguan pola napas tidak efektif di ruang ICVCU RSUD dr Moewardi. Ny. A telah dilakukan pengkajian sampai evaluasi pada tanggal 05 - 08 Maret 2018, sedangkan Ny. S pada tanggal $07-10$ Maret 2018. Pada pembahasan ini akan membandingkan antara konsep teori dan kasus nyata.

1. Pengkajian

a. Ny. A

Pengkajian dilakukan dengan cara wawancara, observasi langsung dan catatan perawatan pasien. Dari hasil pengkajian didapatkan data identitas pasien pertama sebagai berikut nama $\mathrm{Ny}$ A, umur 61 tahun, agama islam, alamat Kedung Miri 04/05 Mantingan, Ngawi. Pendidikan terakhir SD, tidak bekerja, tanggal masuk rumah sakit 03 Maret 2018 pukul $03.45 \mathrm{WIB}$, nomor RM 014xxxx dengan diagnosa medis NSTEMI (Non ST - Elevasi Miokardium). Dilakukan pengkajian pada tanggal 5 maret 2018 pukul 17.00 WIB.

Keluhan utama yang dirasakan pasien yaitu pasien mengatakan sesak napas. Riwayat penyakit sekarang yaitu pasien mengeluhkan sesak napas sejak 6 hari. Keluhan dirasakan hilang timbul yang kemudian bertambah berat jika beraktivitas. Pasien juga mengeluhkan nyeri dada disertai keringat dingin. Oleh keluarga pasien dibawa ke puskesmas dan dirujuk ke RS At Tin Husada. Pasien 
dirawat selama 6 hari. Selama dirawat keluhan tidak juga berkurang dan bertambah berat, oleh dokter pasien dirujuk ke IGD RSUD dr Moewardi pada tanggal 3 Maret 2018 pukul 03.45 WIB. Di IGD pasien mendapat terapi aspilet 80 $\mathrm{mg}$, ISDN $5 \mathrm{mg}$, furosemid $20 \mathrm{mg}$. Kemudian pasien dipindah ke ICVCU pukul 04.25 WIB. Dilakukan pengukuran vital sign sebagai berikut TD : 130/80 mmHg, N : 105 x/menit, RR : 28 x/menit, $\mathrm{S}: 36^{\circ} \mathrm{C} . \quad \mathrm{SpO}_{2} 98 \%$. Kesadaran composmentis. Riwayat penyakit dahulu yaitu keluarga pasien mengatakan pasien mempunyai riwayat penyakit hipertensi, paling tinggi tekanan darah $200 \mathrm{mmHg}$, kolestrol, ginjal. Pasien terakhir mondok 7 bulan yang lalu karena penyakit jantung. Pasien tidak rutin kontrol. Riwayat penyakit keluarga yaitu pasien mengatakan dalam keluarganya tidak ada yang mempunyai riwayat penyakit seperti yang dialami pasien. Tidak mempunyai penyakit yang menurun maupun menular.

Hasil pengkajian primer yaitu airway : Tidak ada obstruksi jalan napas, pasien dapat bernapas spontan, tidak terdapat sumbatan di jalan napas, tidak ada injury pada mulut, hidung, dan tenggorokan. Breathing : Respirasi : 28 $\mathrm{x} /$ menit, menggunakan otot bantu pernapasan, adanya retraksi dinding dada, napas cepat dan dangkal, pasien bernapas spontan support $\mathrm{O}_{2} 3 \mathrm{lpm}$ dengan nasal kanul. Circulation : TD : 130/80 $\mathrm{mmHg}$, $\mathrm{N}: 105 \mathrm{x} /$ menit, CRT < 2 detik, akral hangat pada ekstremitas atas dan bawah, konjungtiva tidak anemis, sklera tidak ikterik. Disability : Tingkat kesadaran composmentis, GCS $\mathrm{E}_{4} \mathrm{M}_{6} \mathrm{~V}_{5}$, KU lemah. Exposure : Tidak terdapat luka pada ekstremitas atas maupun bawah, terpasang infus RL $20 \mathrm{cc} / \mathrm{jam}$ pada tangan kiri.
Hasil pengkajian sekunder yaitu sign and sympthomp : pasien mengeluhkan sesak napas sejak 6 hari. Keluhan dirasakan hilang timbul yang kemudian bertambah berat jika beraktivitas. Respirasi 28 x/menit, napas cepat dan dangkal. Suara napas wheezing. Allergies : pasien tidak mempunyai riwayat alergi terhadap obat maupun makanan. Medication : pasien tidak rutin kontrol. Past illness : Pasien terakhir mondok 7 bulan yang lalu karena penyakit jantung. Last meal : keluarga pasien mengatakan pasien hanya makan 4 sendok dan minum $1 / 2$ gelas sebelum dibawa ke rumah sakit. Event : pasien mengeluhkan sesak napas sejak 6 hari. Keluhan dirasakan hilang timbul yang kemudian bertambah berat jika beraktivitas. Oleh keluarga pasien dibawa ke puskesmas dan dirujuk ke RS At Tin Husada. Pasien dirawat selama 6 hari. Selama dirawat keluhan tidak juga berkurang dan bertambah berat, oleh dokter pasien dirujuk ke IGD RSUD dr Moewardi.

Pemeriksaan head to toe didapatkan hasil keadaan umum baik, kesadaran composmentis, tanda-tanda vital TD : 130/80 mmHg, N : 100 x/menit, RR : 28 $\mathrm{x} /$ menit, $\mathrm{S}: 37^{0} \mathrm{C}$. Pemeriksaan kepala : kepala simetris tidak ada luka/ perdarahan/ benjolan, tidak ada nyeri tekan. Pemeriksaan mata : simetris, konjungtiva anemis, pupil isokor. Pemeriksaan hidung : simetris, bersih, tidak ada sekret, tidak ada polip, tidak ada nyeri tekan. Pemeriksaan telinga : simetris, bersih, tidak ada penumpukan serumen. Pemeriksaan leher : tidak ada jejas, tidak ada pembesaran kelenjar thyroid. Pemeriksaan mulut : tidak ada stomatitis. Pemeriksaan thorax terdiri dari pemeriksaan jantung : inspeksi ictus cordis tak tampak, palpasi tidak ada nyeri 
tekan, perkusi pekak, auskultasi $\mathrm{S}_{1} \mathrm{~S}_{2}$ reguler. Pemeriksaan pulmo : inspeksi terdapat retraksi dinding dada, palpasi tidak ada nyeri tekan, perkusi sonor, auskultasi wheezing. Pemeriksaan abdomen : inspeksi tidak ada lesi, auskultasi bising usus $12 \mathrm{x} / \mathrm{menit}$, palpasi tidak ada nyeri tekan, perkusi tympani. Pemeriksaan integumen : tidak terdapat luka pada ekstremitas, kulit kering, kulit sawo matang, CRT < 2 detik. Pemeriksaan ekstremitas : dapat bergerak aktif, terpasang infus RL 20cc/jam pada tangan kiri. Pemeriksaan genetalia : terpasang DC.

Hasil pemeriksaan penunjang laboratorium pada 03 Maret 2018 antara lain hemoglobin 11,1 gr/dl (normal : 12,0 - 15,6), hematokrit $32 \%$ (normal : 33 45), leukosit 6,9 ribu/ul (normal : 4,5 11,0), trombosit $192 \mathrm{ribu} / \mathrm{ul}$ (normal : 150 - 450), eritrosit 3,48 juta/ul (normal : 4,10 - 5,10), MCV 92,4 /um (normal : 80,0 - 96,0), MCH 31,9 pg (normal : 28,0 - 33,0), MCHC 34,5 g/dl (normal : 33,0 - 36,0), RDW 11,4\% (normal : 11,6 - 14,6), MPV 8,9 fl (normal : 7,2 - 11,1), PDW $16 \%$ (normal : $25-65$ ), eosinofil $0,20 \%$ (normal : $0,00-4,00$ ), basofil $0,10 \%$ (normal : $0,00-2,00$ ), netrofil $90,60 \%$ (normal : 55,00 - 80,00), limfosit 4,30\% (normal : 22,00-44,00), monosit 4,80\% (normal : 0,00-7,00), CKMB 79,45 (normal : $<2,9$ ), golongan darah O. Hasil pemeriksaan EKG pada tanggal 05 Maret 2018 yaitu sinus rhytm, heart rate : $92 \mathrm{bpm}$, normo axis, poor $\mathrm{R}$ wave V1-V3, ST depresi I aVL, T inverted V1.

Program terapi yang didapat yaitu aspilet $80 \mathrm{mg} / 24$ jam, CPG $75 \mathrm{mg} / 24$ jam, bisoprolol 2,5 $\mathrm{mg} / 24 \mathrm{jam}$, atorvastatin $40 \mathrm{mg} / 24 \mathrm{jam}$, ISDN $5 \mathrm{mg} / 8$ jam, captopril 12,5 mg/8 jam, infus RL 20 cc/jam, $\mathrm{O}_{2} 3 \mathrm{lpm}$.

b. Ny. $\mathrm{S}$

Pengkajian dilakukan dengan cara wawancara, observasi langsung dan catatan perawatan pasien. Dari hasil pengkajian didapatkan data identitas pasien pertama sebagai berikut nama $\mathrm{Ny}$ $\mathrm{S}$, umur 71 tahun, agama islam, alamat kwagean gentungan mojogedang karanganyar. Pendidikan terakhir SD, tidak bekerja, tanggal masuk rumah sakit 7 Maret 2018 pukul 15.00 WIB, nomor RM 014xxxx dengan diagnosa medis NSTEMI (Non ST - Elevasi Miokardium). Dilakukan pengkajian pada tanggal 7 maret 2018 pukul 18.00 WIB.

Keluhan utama pasien yaitu pasien mengatakan sesak napas. Riwayat penyakit sekarang yaitu pasien rujukan dari RS dr Oen Surakarta dengan Obs dyspnea 2.C susp CHF obs chest pain. Pasien mengeluhkan sesak napas yang memberat 4 hari terakhir terutama saat aktivitas seperti berjalan ke kamar mandi, pasien tidak bisa tidur karena sesak napas. Pasien juga mengeluhkan batuk tidak berdahak, sesak hilang timbul $<5$ menit disertai keringat dingin. Kemudian pasien dirujuk ke RSUD dr Moewardi pada tanggal 7 maret 2018 pukul 15.00 WIB. Di IGD pasien mendapat terapi aspilet 80 $\mathrm{mg}$, furosemid $40 \mathrm{mg}$, ranitidin $50 \mathrm{mg}$, infus RL $20 \mathrm{cc}$. Kemudian pasien dipindah ke ICVCU pada pukul 15.30 WIB kemudian dilakukan pengukuran vital sign sebagai berikut TD : $130 / 78 \mathrm{mmHg}, \mathrm{N}$ : $99 \mathrm{x} /$ menit, RR : $28 \mathrm{x} /$ menit, $\mathrm{S}: 37^{0} \mathrm{C}$. $\mathrm{SpO}_{2} 97 \%$. Kesadaran composmentis. Riwayat penyakit dahulu yaitu keluarga pasien mengatakan pasien mempunyai riwayat stroke sumbatan, pasien sudah lama tidak mondok. Pasien terakhir mondok di RS dr Oen 1 tahun yang lalu 
karena penyakit jantung. Pasien juga sudah lama tidak kontrol. Riwayat penyakit keluarga yaitu pasien mengatakan dalam keluarganya tidak ada yang mempunyai riwayat penyakit seperti yang dialami pasien. Tidak mempunyai penyakit yang menurun maupun menular.

Hasil pengkajian primer yaitu airway : Tidak ada obstruksi jalan napas, pasien dapat bernapas spontan, tidak terdapat sumbatan di jalan napas, tidak ada injury pada mulut, hidung, dan tenggorokan. Breathing : Respirasi : 28 $\mathrm{x} /$ menit, menggunakan otot bantu pernapasan, adanya retraksi dinding dada, napas cepat dan dangkal, pasien bernapas spontan support $\mathrm{O}_{2} 3 \mathrm{lpm}$ dengan nasal kanul. Circulation : TD : 130/78 $\mathrm{mmHg}$, $\mathrm{N}: 99 \mathrm{x} /$ menit, CRT $<2$ detik, akral hangat pada ekstremitas atas dan bawah, konjungtiva tidak anemis, sklera tidak ikterik. Disability : Tingkat kesadaran composmentis, GCS $\mathrm{E}_{4} \mathrm{M}_{6} \mathrm{~V}_{5}$, KU lemah. Exposure : Tidak terdapat luka pada ekstremitas atas maupun bawah, terpasang infus RL $20 \mathrm{cc} / \mathrm{jam}$ pada tangan kanan.

Hasil pengkajian sekunder yaitu sign and sympthomp : Pasien mengeluhkan sesak napas yang memberat 4 hari terakhir terutama saat aktivitas seperti berjalan ke kamar mandi, pasien tidak bisa tidur karena sesak napas. Respirasi 28 x/menit, napas cepat dan dangkal. Suara napas wheezing. Allergies : pasien tidak mempunyai riwayat alergi terhadap obat maupun makanan. Medication : pasien tidak rutin kontrol. Past illness : Pasien terakhir mondok di RS dr Oen 1 tahun yang lalu karena penyakit jantung. Last meal : keluarga pasien mengatakan pasien hanya makan setengah porsi dan minum $1 / 2$ gelas sebelum dibawa ke rumah sakit. Event : pasien rujukan dari RS dr Oen Surakarta, pasien mengeluhkan sesak napas yang memberat 4 hari terakhir terutama saat aktivitas seperti berjalan ke kamar mandi, pasien tidak bisa tidur karena sesak napas. Kemudian pasien dirujuk ke RSUD dr Moewardi pada tanggal 7 maret 2018 pukul 15.00 WIB.

Pemeriksaan head to toe didapatkan hasil keadaan umum baik, kesadaran composmentis, tanda-tanda vital TD : 120/80 mmHg, $\mathrm{N}: 95$ x/menit, RR : 28 $\mathrm{x} / \mathrm{menit}, \mathrm{S}: 36^{\circ} \mathrm{C}$. Pemeriksaan kepala dan wajah : , kepala simetris tidak ada luka/ perdarahan/ benjolan, tidak ada nyeri tekan. Pemeriksaan mata : simetris, konjungtiva anemis, pupil isokor. Pemeriksaan hidung : simetris, bersih, tidak ada sekret, tidak ada polip, tidak ada nyeri tekan. Pemeriksaan telinga : simetris, bersih, tidak ada penumpukan serumen. Pemeriksaan leher : tidak ada jejas, tidak ada pembesaran kelenjar thyroid. Pemeriksaan mulut : tidak ada stomatitis. Pemeriksaan thorax terdiri dari pemeriksaan jantung : inspeksi ictus cordis tak tampak, palpasi tidak ada nyeri tekan, perkusi pekak, auskultasi reguler. Pemeriksaan pulmo : inspeksi terdapat retraksi dinding dada, palpasi tidak ada nyeri tekan, perkusi sonor, auskultasi wheezing. Pemeriksaan abdomen : inspeksi tidak ada lesi, auskultasi bising usus $12 \mathrm{x} / \mathrm{menit}$, palpasi tidak ada nyeri tekan, perkusi tympani. Pemeriksaan integumen : tidak terdapat luka pada ekstremitas, kulit kering, kulit sawo matang, CRT $<2$ detik. Pemeriksaan ekstremitas : dapat bergerak aktif, terpasang infus RL 20cc/jam pada tangan kiri. Pemeriksaan genetalia : terpasang DC.

Hasil pemeriksaan penunjang laboratorium pada 03 Maret 2018 antara 
lain hemoglobin 7,6 gr/dl (normal : 12,0 - 15,6), hematokrit $27 \%$ (normal : 33 45), leukosit 4,9 ribu/ul (normal : 4,5 11,0), trombosit $286 \mathrm{ribu} / \mathrm{ul}$ (normal : 150 - 450), eritrosit 4,14 juta/ul (normal : 4,10 - 5,10), MCV 64,6 /um (normal : 80,0 - 96,0), MCH 18,4 pg (normal : 28,0 - 33,0), MCHC 28,5 g/dl (normal : 33,0 - 36,0), RDW 19,3\% (normal : 11,6 - 14,6), MPV 8,1 fl (normal : 7,2 - 11,1), PDW $15 \%$ (normal : $25-65$ ), eosinofil $4,40 \%$ (normal : $0,00-4,00$ ), basofil $0,30 \%$ (normal : $0,00-2,00$ ), netrofil $45,20 \%$ (normal : 55,00 - 80,00), limfosit 43,40 \% (normal : 22,00 44,00), monosit 6,70\% (normal : 0,00 7,00), golongan darah B. GDS $102 \mathrm{mg} / \mathrm{dl}$. Hasil pemeriksaan EKG pada tanggal 07 Maret 2018 yaitu sinus rhytm, heart rate : 80 bpm, normo axis, ST depresi I II aVL aVF V5-V6, T inverted V1-V6. Hasil foto thorax yang didapat pada tanggal 03 Maret 2018 adalah foto thorax AP view, hasil cardhiomegaly disertai oedema pulmo.

Program terapi yang didapat yaitu aspilet $80 \mathrm{mg} / 24$ jam, CPG $75 \mathrm{mg} / 24$ jam, furosemid $20 \mathrm{mg} / 8 \mathrm{jam}$, atorvastatin $20 \mathrm{mg} / 24 \mathrm{jam}$, ISDN $5 \mathrm{mg} / 8 \mathrm{jam}$, ranitidin $50 \mathrm{mg} / 12 \mathrm{jam}$, fondaparinux 2,5 $\mathrm{mg} / 24$ jam, ramipril 2,5 mg/24 jam, novorapid 4-4-4 unit, infus RL 20 cc/jam, $\mathrm{O}_{2} 3 \mathrm{lpm}$.

2. Diagnosa Keperawatan

Pola napas tidak efektif berhubungan dengan penurunan suplai oksigen

3. Intervensi

Berdasarkan dianosa keperawatan yang telah dirumuskan dapat disusun rencana keperawatan yaitu diagnosa pola napas tidak efektif berhubungan dengan penurunan suplai oksigen, tujuan yang ingin dicapai setelah dilakukan tindakan keperawatan selama 3 x 8 jam diharapkan pola napas kembali efektif dengan kriteria hasil : menujukkan jalan napas yang paten (klien tidak merasa tercekik, irama napas, frekuensi pernapasan dalam rentang normal, tidak ada suara napas abnormal, tidak sesak napas), RR dalam batas normal 16-20 x/menit, SpO2 dalam batas normal, tekanan darah normal, frekuensi jantung 60-100 kali/menit. Rencana tindakan observasi tanda-tanda vital, SpO2, dan frekuensi jantung (R: Perubahan tekanan darah menunjukkan efek hipoksia sistemik pada fungsi jantung), auskultasi suara napas, catat adanya bunyi napas (R: Dapat mengidentifikasi edema paru), atur posisi semifowler (R: Meningkatkan ekspansi paru dan memudahkan pernapasan), ajarkan pasien pernapasan diafragma $(\mathrm{R}$ : Membantu pasien memperpanjang waktu ekspirasi, dengan teknik ini pasien akan bernapas lebih efisien dan efektif), kolaborasi dalam pemberian oksigen (R: Meningkatkan jumlah oksigen untuk meringankan kerja miokardia).

4. Implementasi

a. Ny. A

Pada pasien Ny A implementasi yang dilakukan tanggal 06 Maret 2018 adalah mengobservasi tanda-tanda vital, $\mathrm{SpO} 2$, frekuensi jantung (16.00 WIB), mengauskultasi suara napas dan mencatat adanya bunyi napas (16.15 WIB), mengatur posisi semifowler (17.00 WIB), mengajarkan pasien pernapasan diafragma (17.15 WIB), berkolaborasi dalam pemberian oksigen (17.30 WIB). Kemudian implementasi hari kedua pada tanggal 07 Maret 2018 adalah mengobservasi tanda-tanda vital, $\mathrm{SpO}$, frekuensi jantung (17.00 WIB), mengauskultasi suara napas dan mencatat adanya bunyi napas (17.15 WIB), 
mengatur posisi semifowler (18.00 WIB), menganjurkan pasien pernapasan diafragma (18.15 WIB), berkolaborasi dalam pemberian oksigen (18.30 WIB). Implementasi hari ketiga pada tanggal 08 Maret 2018 mengobservasi tanda-tanda vital, SpO2, frekuensi jantung (16.00 WIB), mengauskultasi suara napas dan mencatat adanya bunyi napas (16.15 WIB), mengatur posisi semifowler (17.00 WIB), menganjurkan pasien pernapasan diafragma (17.15 WIB), berkolaborasi dalam pemberian oksigen (17.30 WIB). b. Ny. S

Pada pasien Ny $\mathrm{S}$ implementasi yang dilakukan tanggal 08 Maret 2018 adalah mengobservasi tanda-tanda vital, $\mathrm{SpO} 2$, frekuensi jantung (16.30 WIB), mengauskultasi suara napas dan mencatat adanya bunyi napas (16.45 WIB), mengatur posisi semifowler (17.10 WIB), mengajarkan pasien pernapasan diafragma (17.30 WIB), berkolaborasi dalam pemberian oksigen (18.00 WIB). Kemudian implementasi hari kedua pada tanggal 09 Maret 2018 adalah mengobservasi tanda-tanda vital, $\mathrm{SpO} 2$, frekuensi jantung (17.30 WIB), mengauskultasi suara napas dan mencatat adanya bunyi napas (17.45 WIB), mengatur posisi semifowler (18.00 WIB), menganjurkan pasien pernapasan diafragma (18.15 WIB), berkolaborasi dalam pemberian oksigen (18.30 WIB). Implementasi hari ketiga pada tanggal 10 Maret 2018 mengobservasi tanda-tanda vital, SpO2, frekuensi jantung (16.00 WIB), mengauskultasi suara napas dan mencatat adanya bunyi napas (16.15 WIB), mengatur posisi semifowler (17.00 WIB), menganjurkan pasien pernapasan diafragma (17.15 WIB), berkolaborasi dalam pemberian oksigen (17.30 WIB). 4. Evaluasi
Evaluasi yang didapat pada $\mathrm{Ny}$. A dengan hasil subjektif (S) pasien mengatakan sesak napas berkurang dan objektif $(\mathrm{O})$ suara napas vesikuler, tidak terdapat retraksi dinding dada, tidak menggunakan otot bantu pernapasan, tanda-tanda vital TD : 120/80 $\mathrm{mmHg}$, HR $90 \mathrm{x} /$ menit, RR : $22 \mathrm{x} /$ menit, $\mathrm{S}: 36,5^{\circ} \mathrm{C}$, $\mathrm{SpO} 299 \%$, dengan analisa keperawatan (A) masalah pola napas tidak efektif teratasi sebagian sehingga rencana tindak lanjut (P) intervensi masih perlu dilanjutkan. Sedangkan evaluasi yang didapat pada Ny. S dengan hasil subjektif (S) pasien mengatakan masih sesak napas dan objektif $(\mathrm{O})$ suara napas wheezing, terdapat retraksi dinding dada, menggunakan otot bantu pernapasan, pasien tampak lemah, tanda-tanda vital TD : 130/80 mmHg, HR 75 x/menit, RR : $28 \mathrm{x} /$ menit, $\mathrm{S}: 36,7^{\circ} \mathrm{C}, \mathrm{SpO} 298 \%$, dengan analisa keperawatan (A) masalah pola napas tidak efektif belum teratasi sehingga rencana tindak lanjut $(\mathrm{P})$ intervensi masih perlu dilanjutkan.

\section{PEMBAHASAN}

Pada pembahasan ini, peneliti menjelaskan dua pasien Acute Myocard Infark (AMI) dengan gangguan pola napas tidak efektif saat sebelum diberi tindakan dan sesudah diberi tindakan. Kemudian peneliti membandingkan hasil dari masing-masing pasien setelah dilakukan tindakan keperawatan yang didukung oleh teori dan jurnal.

Pengkajian pada Ny. A didapatkan data pasien mengatakan sesak napas disertai nyeri dada, suara napas wheezing, terdapat retraksi dinding dada, menggunakan otot bantu pernapasan, RR : 28 x/menit, SpO2 $98 \%$ TD : 130/80 mmHg, HR: $105 \mathrm{x} /$ menit. Dari data tersebut maka dapat ditegakkan diagnosa 
keperawatan pola napas tidak efektif berhubungan dengan penurunan suplai oksigen. Setelah disusun intervensi keperawatan dan kemudian dilakukan implementasi keperawatan selama $3 \times 8$ jam diperoleh hasil dari respon pasien. Pasien mengatakan sesak napas berkurang, suara napas vesikuler, tidak terdapat retraksi dinding dada, tidak menggunakan otot bantu pernapasan, tanda-tanda vital TD : $120 / 80 \mathrm{mmHg}, \mathrm{HR}$ 90 x/menit, RR : $22 \mathrm{x} / \mathrm{menit} \mathrm{S}: 36,5^{\circ} \mathrm{C}$, SpO2 $99 \%$. Dari hasil tersebut maka masalah keperawatan teratasi sebagian dan intervensi dilanjutkan.

Pengkajian pada Ny. S didapatkan data pasien mengatakan sesak napas, suara napas wheezing, terdapat retraksi dinding dada, menggunakan otot bantu pernapasan, RR : 28 x/menit, SpO2 $97 \%$, TD : 130/78 mmHg, HR : 99 x/menit. Dari data tersebut maka dapat ditegakkan diagnosa keperawatan pola napas tidak efektif berhubungan dengan penurunan suplai oksigen. Setelah disusun intervensi keperawatan dan kemudian dilakukan implementasi keperawatan selama $3 \times 8$ jam diperoleh hasil dari respon pasien. Pasien mengatakan masih sesak napas, suara napas wheezing, terdapat retraksi dinding dada, menggunakan otot bantu pernapasan, pasien tampak lemah, tandatanda vital TD : 130/80 $\mathrm{mmHg}$, HR 75 $\mathrm{x} /$ menit, RR : 28 x/menit, $\mathrm{S}: 36,7^{0} \mathrm{C}$, $\mathrm{SpO} 298 \%$. Dari hasil tersebut maka masalah keperawatan belum teratasi dan intervensi dilanjutkan.

Berdasarkan kriteria hasil didapatkan perbedaan yaitu Ny A sesak napas berkurang sedangkan $\mathrm{Ny} \mathrm{S}$ tidak berkurang. Pada Ny A sesak napas disebabkan karena nyeri, sehingga jika nyeri berkurang sesak napas pun berkurang. Pada Ny A sebelumnya mengeluhkan sesak napas dan nyeri dada disertai keringat dingin, berdasarkan teori pada pasien Non ST - Elevasi Miokardium (NSTEMI) terjadi gangguan suplai oksigen maka jantung akan melakukan metabolisme anaerob agar jantung tetap memberikan suplai oksigen keseluruh tubuh. Menurut Kastron (2012) hasil dari metabolisme anaerob berupa asam laktat, inilah yang menyebabkan nyeri dada seperti diremas-remas, ditekan, ditusuk, panas, atau ditindih barang berat pada dada depan (bawah sternum) serta menjalar ke dagu, leher kiri, punggung, dan epigastrium. Nyeri dada disertai sesak nafas. Sedangkan pada Ny S sesak napas disebabkan oleh diagnosa medis yang terkait yaitu Obs dyspnea 2.C susp CHF. Sebelumnya Ny $S$ hanya mengeluhkan sesak napas disertai keringat dingin. Menurut Kastron (2012) sesak napas dapat ditemukan pada awal serangan tanpa nyeri dada. Sesak napas terjadi karena pengerahan tenaga dan kenaikan tekanan akhir diastolic ventrikel kiri yang meningkatkan tekanan vena pulmonalis. Aktivitas pasien seringkali juga mengalami perubahan. Pasien sering merasa kelemahan, kelelahan, tidak dapat tidur, dan pola hidup menetap (bedrest). Karena aktivitas dapat memicu peningkatan kerja jantung, sehingga sesak napas dapat terjadi.

Pada pasien Ny $S$ tidak merasakan nyeri dada karena Ny S menderita diabetes mellitus dengan GDS 200. Menurut Muttaqin (2009) pasien dengan diabetes melitus tidak akan mengalami nyeri yang hebat karena neuropati yang menyertai diabetes dapat mengganggu neuroreseptor (mengumpulkan pengalaman nyeri). Pada pasien Ny S suara napas wheezing dan batuk karena mengalami oedema pulmo. 
Hasil foto thorax AP view, hasil cardhiomegaly disertai oedema pulmo.

Pada Ny A respirasi dari $28 \mathrm{x} / \mathrm{menit}$ menjadi $22 \mathrm{x} / \mathrm{menit}$, suara napas vesikuler, tidak terdapat retraksi dinding dada dan tidak menggunakan otot bantu pernapasan sedangkan pada $\mathrm{Ny} \mathrm{S}$ dari 28 $\mathrm{x} /$ menit tidak mengalami penurunan tetap $28 \mathrm{x} /$ menit, suara napas wheezing, terdapat retraksi dinding dada, dan menggunakan otot bantu pernapasan. Hal tersebut dikarenakan $\mathrm{Ny}$ A sesak napas berkurang dan kadar hemoglobin dari $11,1 \mathrm{~g} / \mathrm{dl}$ menjadi 11,6 g/dl. Sedangkan Ny S sesak napas tidak berkurang dan kadar hemoglobin yang rendah yaitu 7,6 g/dl menjadi 8,6 g/dl. Kadar hemoglobin yang rendah, dapat mengurangi pasokan oksigen yang sampai ke jaringan. Selain itu, rendahnya pasokan oksigen akan menstimulasi otak untuk meningkatkan laju pernapasan guna mengembalikan kadar oksigen kembali ke normal. Karena itulah, jika kadar hb rendah akan merasakan sesak napas dan perlu bernapas lebih cepat dari biasanya.

Perubahan saturasi oksigen pada Ny A dari $98 \%$ menjadi $99 \%$, sedangkan pada Ny S dari $97 \%$ menjadi $98 \%$. Masing-masing mengalami peningkatan $1 \%$, hal ini karena terapi oksigen yang sama-sama diberikan yaitu $3 \mathrm{lpm}$ melalui nasal kanul. Berdasarkan jurnal Budi Widiyanto dan L. S. Yamin (2014) bahwa dengan terapi oksigen binasal kanul dapat mengembalikan saturasi oksigen dari kondisi hipoksia ringan ke kondisi normal secara bermakna. Dimana pada pasien dengan infark miokard terjadi sumbatan ataupun penyempitan arteri koroner secara mendadak yang menyebabkan jaringan miokard mengalami iskemik, maka dengan pemberian terapi oksigen dapat mempengaruhi tonus otot arteri sehingga menyebabkan vasodilatasi dari arteri koroner (sebagaimana kondisi hipoksia dapat menyebabkan vasokonstriksi arteri koroner), sehingga suplai darah dan oksigen ke jaringan miokard yang mengalami iskemik dapat kembali baik yang pada akhirnya dapat mempertahankan fungsi pompa ventrikel dan fungsi sistim kardiovaskuler secara umum sebagai salah satu sistim transportasi oksigen yang menentukan saturasi oksigen.

Faktor-faktor lain yang menyebabkan perbedaan kriteria hasil, dimana pada $\mathrm{Ny}$ A teratasi sebagian dan $\mathrm{Ny} \mathrm{S}$ belum teratasi antara lain usia $\mathrm{Ny} \mathrm{S}$ yang lebih tua yaitu 71 tahun dengan mempunyai riwayat penyakit stroke sumbatan, penyakit jantung yang sama, hipertensi dan DM. Sedangkan usia Ny A 61 tahun dengan mempunyai riwayat penyakit hipertensi, kolestrol dan penyakit jantung yang sama. Usia merupakan faktor biologis yang tidak dapat diubah dimana pada usia tersebut terjadi penurunan kontraktilitas otot jantung.

\section{KESIMPULAN DAN SARAN}

Setelah dilakukan asuhan keperawatan pada Ny. A dan Ny. S dengan Acute Myocard Infark (AMI) di ruang ICVCU RSUD dr. Moewardi peneliti membuat beberapa kesimpulan:

1. Sebelum dilakukan asuhan keperawatan Ny. A mengatakan sesak napas, suara napas wheezing, terdapat retraksi dinding dada, menggunakan otot bantu pernapasan, RR : $28 \mathrm{x} /$ menit, SpO2 $98 \%$ TD : 130/80 mmHg, HR: $105 \mathrm{x} / \mathrm{menit}$ dapat ditegakkan diagnosa keperawatan pola napas tidak efektif kemudian dilakukan asuhan keperawatan selama $3 \times 8$ jam diperoleh 
hasil evaluasi yaitu masalah teratasi sebagian.

2. Sebelum dilakukan asuhan keperawatan Ny. S mengatakan sesak napas, suara napas wheezing, terdapat retraksi dinding dada, menggunakan otot bantu pernapasan, RR : 28 x/menit, SpO2 $97 \%$, TD : 130/78 $\mathrm{mmHg}, \quad \mathrm{HR}$ : $99 \mathrm{x} / \mathrm{menit}$ dapat ditegakkan diagnosa keperawatan pola napas tidak efektif kemudian dilakukan asuhan keperawatan selama $3 \times 8$ jam diperoleh hasil evaluasi yaitu masalah belum teratasi.

3. Ada perbedaan setelah dilakukan asuhan keperawatan pada $\mathrm{Ny}$. A dan Ny. S dengan gangguan pola napas tidak efektif.

Dari kesimpulan di atas, ada beberapa hal yang perlu diperhatikan dalam pemberian asuhan keperawatan pada kedua pasien, yaitu:

1. Dalam penggalian data juga diperlukan kejelian dan ketelitian sehingga akan didapatkan data-data yang dibutuhkan untuk menegakkan diagnosa keperawatan yang ada dalam teori. Selain itu, dapat segera diketahui dan ditangani secara tepat.

2. Pada saat menegakkan diagnosa keperawatan, sebaiknya perawat lebih menggali kajian teori dan data yang ada pada kasus sehingga dalam perumusan diagnosa dapat lebih tepat dan sesuai dengan keadaan klien.

3. Pada saat menyusun intervensi keperawatan, sebaiknya perawat harus dapat menyesuaikan dengan kondisi klien dan mampu menerapkan teori dengan kasus nyata yang dihadapi sehingga tercapai asuhan keperawatan yang komprehensif.

4. Pada saat menyusun implementasi dalam pemberian asuhan keperawatan pada klien, bekerja sama antara tim kesehatan perlu dipertahankan dan lebih ditingkatkan untuk mendapatkan hasil yang optimal.

5. Pada saat menyusun evaluasi keperawatan harus disesuaikan dengan kriteria hasil dan tujuan yang ditetapkan pada intervensi dan diperlukan berpikir kritis untuk mengevaluasi tindakan keperawatan.

\section{DAFTAR RUJUKAN}

Andarmoyo, Sulistyo. (2012). Kebutuhan Dasar Manusia Oksigenasi Konsep Proses dan Praktik Keperawatan. Yogyakarta: Graha Ilmu

Badan Penelitian dan Pengembangan Departemen Kesehatan RI. (2013). Riskesdas 2013. Diakses 25 Oktober 2017 (10.00), dari http://www.depkes.go.id/resources/ download/general/Hasil\%20Riskes das\%202013.pdf

Black, Joyce \& Jane Hokanson Hawks. 2014. Keperawatan Medikal Bedah Manajemen Klinis Untuk Hasil yang Diharapkan Edisi 8. Jakarta: Salemba Medika

Corwin, E.J. (2009). Buku saku Patofisiologi. Jakarta: EGC

Debora, O. (2013). Proses Keperawatan dan Pemeriksaan Fisik. Jakarta: Salemba Medika

Depkes RI, (2011). Profil Kesehatan Indonesia 2010. Diakses 28 November 2017 (09.45) dari http://www.depkes.go.id.

Djojodibroto, Darmanto. (2012). Respirologi (Respiratory Medicine). Jakarta : EGC

Doengoes, Marilyn E. (2000). Rencana Asuhan Keperawatan. Jakarta: EGC 
Hidayat, A. A. (2014). Metode Penelitian Kebidanan dan Teknik Analisis Data. Jakarta: Salemba Medika

Kartikawati, dewi. (2014). Buku Ajar Dasar-Dasar Keperawatan Gawat Darurat. Jakarta: Salemba Medika

Kastron. (2012). Buku Ajar Gangguan System Kardiovaskuler. Yogyakarta: Nuha Medika

Morton, P. G, Hudak, C. M, \& Gallo, B. M. (2011). Keperawatan Kritis: Pendekatan Asuhan Holistik. Edisi 8 Volume 1. Jakarta: EGC

Muttaqin, Arif. (2009). Asuhan Keperawatan Klien dengan Gangguan Sistem Kardiovaskuler dan Hematologi. Jakarta: Salemba Medika

Nurarif, Amin Huda \& Hardhi Kusuma. (2015). Aplikasi Asuhan Keperawatan Berdasarkan Diagnosa Medis \& NANDA NIC NOC. Yogyakarta: MediAction

Nursalam. (2016). Metodologi Penelitian Ilmu Keperawatan Pendekatan Praktis. Jakarta: Salemba Medika

Potter, P. A., \& Perry, A.G. (2006). Buku Ajar Fundamental Keperawatan: Konsep, Proses, dan Praktik. Jakarta : EGC .(2009). Fundamental of Nursing: Concept process and pratice, Edisi 4. Jakarta: EGC

Saputra, Lyndon. (2013). Pengantar Kebutuhan Dasar Manusia. Tangerang: Binarupa Aksara Publisher

Smeltzer, Suzzane C \& Bare, Brenda G. (2002). Buku Ajar Keperawatan Medikal Bedah Brunner \& Suddarth. Jakarta: EGC
Siregar, Y. F. (2010). Hubungan Antara Luas Infark Miokard Berdasarkan Hasil EKG dengan Kadar Troponin T pada Penderita Infark Miokard Akut STEMI dan Non STEMI di RSUP H. Adam Malik Medan. Diakses 15 November 2017 (10.00), dari http://repository.usu.ac.id/bitstrea $\mathrm{m} / 123456789 / 22069 / 5 /$ Chapter\%2 01.pdf

Tarwoto \& Wartonah. (2015). Kebutuhan Dasar Manusia dan Proses Keperawatan. Jakarta: Salemba Medika

Thygesen, K., Alpert, J.S., Jaffe, A.S., Simoons, M.L., Chaitman, B.R., \& White, H.D. (2012). Third Universal Definition of Myocardial Infarction: European Heart Journal (2012), 33, 2551-2567. Diakses 28 November 2017 (09.30), dari http://eurheartj. Oxfordjournals.org/content/early/2 012/08/23/eurheartj.ehs184.

Tim Pokja SDKI DPP PPNI. (2017). Standar Diagnosis Keperawatan Indonesia Definisi dan Indikator Diagnostik Edisi 1. Jakarta: DPP PPNI

Udjianti, W. J. (2011). Keperawatan Kardiovaskuler. Jakarta: Salemba Medika

Vaughans, Bennita W. (2013). Keperawatan Dasar. Yogyakarta: Rapha Publishing

Velkumary, G.K.P.S., \& Madanmohan. (2004). Effect of Short-term Pratice of Breathing Exercise on Autonomic Function in Normal Human Volunteers. Indian Journal Respiration, (120), 115-121. Diakses 24 Oktober 2017 (17.01), dari 
http://www.ncbi.nlm.nih.gov/pub med/15347862.

Widiyanto, Budi \& L. S. Yamin. (2014). Terapi Oksigen Terhadap Perubahan Saturasi Oksigen Melalui Pemeriksaan Oksimetri Pada Pasien Infark Miokard Akut (IMA). Diakses 17 Mei 2018 (20.00), dari https://jurnal.unimus.ac.id/index.p hp/psn12012010/article/view/113 5

Yudha, Armada Karima. (2016). Hubungan Tingkat Kecemasan dengan Lama Hari Rawat pada Pasien Akut Miokard Infark (AMI) di Ruang ICVCU RSUD dr. Moewardi. Surakarta: Poltekkes Kemenkes Surakarta 